\title{
Front Matter: Volume 7125
}

, "Front Matter: Volume 7125," Proc. SPIE 7125, Eighth International Symposium on Optical Storage and 2008 International Workshop on Information Data Storage, 712501 (10 April 2009); doi: 10.1117/12.831140 SPIE. Event: Eighth International Symposium on Optical Storage and 2008 


\section{PROCEEDINGS OF SPIE}

\section{Eighth International Symposium on \\ Optical Storage and 2008 International Workshop on Information Data Storage}

Fuxi Gan

Editor

24-27 November 2008

Wuhan, China

Sponsored and Organized by

Shanghai Institute of Optics and Fine Mechanics, CAS (China) • Wuhan National Laboratory for Optoelectronics (China)

\section{Cosponsored by}

National Natural Science Foundation of China $\bullet$ Wuhan National Optoelectronics Information Industrial Base (China) • Fudan University (China) • Disc Industry Promotion Committee of China, China Audio Industries Association • Optical Disc Committee, China Audio/Video Association

\section{Co-Organized by}

Wuhan Hi-Tech Holding Group Company, Ltd. (China) • National Engineering Research Center for Optical Discs and Applications (China) - Optical Memory National Engineering Research Center (China) • Wuhan Optics Valley NOE-Tech Development Company, Ltd. (China)

Published by

SPIE

Volume 7125 
The papers included in this volume were part of the technical conference cited on the cover and title page. Papers were selected and subject to review by the editors and conference program committee. Some conference presentations may not be available for publication. The papers published in these proceedings reflect the work and thoughts of the authors and are published herein as submitted. The publisher is not responsible for the validity of the information or for any outcomes resulting from reliance thereon.

Please use the following format to cite material from this book:

Author(s), "Title of Paper," in Eighth International Symposium on Optical Storage and 2008 International Workshop on Information Data Storage, edited by Fuxi Gan, Proceedings of SPIE Vol. 7125 (SPIE, Bellingham, WA, 2009) Article CID Number.

ISSN 0277-786X

ISBN 9780819473592

Published by

SPIE

P.O. Box 10, Bellingham, Washington 98227-0010 USA

Telephone +1 3606763290 (Pacific Time) · Fax +1 3606471445

SPIE.org

Copyright (C) 2009, Society of Photo-Optical Instrumentation Engineers

Copying of material in this book for internal or personal use, or for the internal or personal use of specific clients, beyond the fair use provisions granted by the U.S. Copyright Law is authorized by SPIE subject to payment of copying fees. The Transactional Reporting Service base fee for this volume is $\$ 18.00$ per article (or portion thereof), which should be paid directly to the Copyright Clearance Center (CCC), 222 Rosewood Drive, Danvers, MA 01923. Payment may also be made electronically through CCC Online at copyright.com. Other copying for republication, resale, advertising or promotion, or any form of systematic or multiple reproduction of any material in this book is prohibited except with permission in writing from the publisher. The CCC fee code is 0277-786X/09/\$18.00.

Printed in the United States of America.

Publication of record for individual papers is online in the SPIE Digital Library.

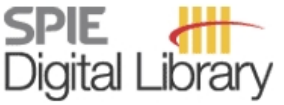

SPIEDigitalLibrary.org

Paper Numbering: Proceedings of SPIE follow an e-First publication model, with papers published first online and then in print and on CD-ROM. Papers are published as they are submitted and meet publication criteria. A unique, consistent, permanent citation identifier (CID) number is assigned to each article at the time of the first publication. Utilization of CIDs allows articles to be fully citable as soon they are published online, and connects the same identifier to all online, print, and electronic versions of the publication. SPIE uses a six-digit CID article numbering system in which:

- The first four digits correspond to the SPIE volume number.

- The last two digits indicate publication order within the volume using a Base 36 numbering system employing both numerals and letters. These two-number sets start with 00, 01, 02, 03, 04 , 05, 06, 07, 08, 09, OA, OB ... 0Z, followed by 10-1Z, 20-2Z, etc.

The CID number appears on each page of the manuscript. The complete citation is used on the first page, and an abbreviated version on subsequent pages. Numbers in the index correspond to the last two digits of the six-digit CID number. 


\section{Contents}

xi Conference Committees

\section{SESSION 1 HIGH DENSITY OPTICAL STORAGE}

712502 Next generation storage technology in magnetic and optical recording system [7125-140] Y.-P. Park, K.-S. Park, N.-C. Park, Yonsei Univ. (Korea, Republic of)

712503 Theory and practice of multilevel method in high-definition discs [7125-96] J. Pei, L. Li, H. Xu, L. Pan, Tsinghua Univ. (China)

712504 Volume holographic storage using phenanthrenequinone-doped poly (methyl methacrylate) photopolymer [7125-52]

J. Wang, X. Sun, Harbin Institute of Technology (China)

712505 Super-resolution nanopatterns and optical recording in chalcogenide phase change thin films by direct laser writing [7125-152]

J. Wei, X. Jiao, Shanghai Institute of Optics and Fine Mechanics (China)

712506 Restrictions on pit length in multi-level read-only disk [7125-53]

L. Li, B. Yang, Y. Tang, L. Pan, J. Pei, Tsinghua Univ. (China)

712507 Influence of servo error on the readout signal for a multi-level DVD using waveform modulation [7125-91]

Y. Tang, J. Pei, L. Pan, H. Xu, M. Yan, Tsinghua Univ. (China)

712508 Readout system of multi-level run-length-limited read-only disc [7125-68] H. Wang, H. XU, L. Pan, M. Yan, Tsinghua Univ. (China)

712509 Polarization holographic optical recording of a new photochromic diarylethene [7125-34] S. Pu, W. Miao, A. Chen, S. Cui, Jiangxi Science and Technology Normal Univ. (China)

$71250 \mathrm{~A}$ A method of 3-D data information storage with virtual holography [7125-25]

Z. Huang, G. Liu, Z. Ren, L. Zeng, Jiangxi Science and Technology Normal Univ. (China)

$7125 \mathrm{OB}$ Synthesis, photochromism, and holographic optical recording of photochromic diarylethene bearing fluorine atoms [7125-39]

G. Liu, S. Pu, C. Fan, W. Liu, Jiangxi Science and Technology Normal Univ. (China)

7125 OC Dynamics analysis of erythrosine B sensitized photopolymer holographic gratings [7125-28] K. Chen, J.-Q. Cheng, Y. Wang, M.-J. Huang, Henan Univ. (China)

7125 OD Analysis of the push-pull signal in the multi-level run-length-limited read-only disc [7125-01] M. Yan, J. Pei, L. Pan, H. Wang, Tsinghua Univ. (China) 
$7125 \mathrm{OE} \quad$ A method of 3D data information encryption with virtual holography [7125-27] Z. Huang, G. Liu, Z. Ren, L. Zeng, Jiangxi Science and Technology Normal Univ. (China)

7125 OF Angular selectivity of a spherical reference wave holographic storage system [7125-12] S. Luo, Y. Zhang, Q. Meng, Y. Jiang, X. Sun, Harbin Institute of Technology (China)

7125 OG Holographic scattering in phenanthrenequinone-doped poly(methyl methacrylate) bulk photopolymers [7125-32]

H. Liu, D. Yu, X. Sun, Harbin Institute of Technology (China)

$7125 \mathrm{OH} \quad$ Comparison of high-density holographic characteristics of photopolymers sensitized by two kinds of thiazine dyes [7125-21]

J. Cheng, K. Chen, Y. Wang, M. Huang, Henan Univ. (China)

7125 Ol New interleaving scheme for error correction code of a multilevel optical storage system [7125-62]

H. Liu, L. Pan, B. Hu, X. Liu, Tsinghua Univ. (China)

$71250 \mathrm{~J}$ Strategies for employing nano-heterostructures in a near-field enhanced super-resolution optical disk [7125-160]

Y. Wang, Q. Qu, Shanghai Institute of Optics and Fine Mechanics (China)

7125 OK Static recording properties of super-resolution near-field structure with antimony bismuth mask layer [7125-128]

L. Jiang, Shanghai Institute of Optics and Fine Mechanics (China); Y. Wu, Shanghai Institute of Optics and Fine Mechanics (China) and Heilongjiang Univ. (China); Y. Wang, J. Wei,

F. Gan, Shanghai Institute of Optics and Fine Mechanics (China)

$7125 \mathrm{OL}$ Research progress of super-resolution near-field structure (super-RENS) for optical storage [7125-121]

J.-X. Yi, Tsinghua Univ. (China); J.-W. Woo, Y.-S. Park, Sangmyung Univ. (Korea, Republic of);

F.-S. Zhang, Tsinghua Univ. (China)

\section{SESSION 2 OPTICS AND MAGNETICS FOR HYBRID RECORDING}

7125 OM High-coercivity SmCo5 thin film with in-plane or out-of-plane anisotropy [7125-35] L. N. Zhang, National Univ. of Singapore (Singapore); J. F. Hu, Data Storage Institute (Singapore); J. S. Chen, J. Ding, National Univ. of Singapore (Singapore)

$7125 \mathrm{ON}$ The influence of porous alumina underlayer on structure and magnetization reverals of hybrid recording media [7125-86]

J. B. Yan, Wuhan National Lab. for Optoelectronics (China) and ShangDong SinoChip Semiconductors Ltd. (China); Z. Y. Li, K. F. Dong, P. Li, G. Q. Lin, Huazhong Univ. of Science and Technology (China); X. S. Miao, Wuhan National Lab. for Optoelectronics (China) and Huazhong Univ. of Science and Technology (China)

712500 Micromagnetic simulation of microwave assisted switching in $\mathrm{Ni}_{80} \mathrm{Fe}_{20}$ thin film element [7125-80]

P. Li, X. Yang, X. Cheng, Huazhong Univ. of Science and Technology (China) 
7125 OP High density magneto-optical data storage based on magnetically induced superresolution and blue wavelength [7125-133]

J. Wang, Shanghai Normal Univ. (China) and Shanghai Institute of Technology (China);

X. Wang, M. Jin, Shanghai Institute of Technology (China)

$7125 \mathrm{OQ}$ Improving the lookup performance of peer-to-peer storage via proxy-based hierarchy chord [7125-151]

H. Zhong, D. Luo, W. Wu, L. Xiao, Wuhan National Lab. for Optoelectronics, Huazhong Univ. of Science and Technology (China)

7125 OR Laser assisted magnetic recording properties using SiAg near-field super-resolution structure [7125-106]

X. Jiao, J. Wei, F. Gan, Shanghai Institute of Optics and Fine Mechanics (China)

7125 OS Effect of thin carbon layer insertion on the magnetic property and microstructure of CoCrPt/Ti hybrid recording media [7125-93]

X. M. Cheng, X. S. Miao, X. F. Yang, Z. Li, G. Q. Lin, Z. Y. Li, Huazhong Univ. of Science and Technology (China)

7125 OT The effect of different cooling processes on the microstructure and magnetic properties of FePt single layer films [7125-18]

K. Dong, X. Yang, X. Miao, Huazhong Univ. of Science and Technology (China); X. Xu, Shanxi Normal Univ. (China); X. Cheng, Huazhong Univ. of Science and Technology (China); F. Wang, Shanxi Normal Univ. (China); J. Yan, W. Cheng, Huazhong Univ. of Science and Technology (China)

$7125 \mathrm{OU}$ The influence of underlayers on the magnetic properties of TbFeCo films for hybrid recording [7125-87]

W. Cheng, X. Miao, Huazhong Univ. of Science and Technology (China) and Wuhan National Lab. for Optoelectronics (China); J. Yan, Wuhan National Lab. for Optoelectronics, Huazhong Univ. of Science and Technology (China); G. Lin, Huazhong Univ. Of Science and Technology (China) and Wuhan National Lab. for Optoelectronics (China)

\section{SESSION 3 MATERIALS FOR OPTICAL STORAGE}

$7125 \mathrm{OV}$ Synthesis of photochromic diarylethene for rewritable holographic optical storage [7125-42] W. Miao, S. Pu, W. Liu, C. Fan, Jiangxi Science and Technology Normal Univ. (China)

7125 OW Spirooxazine-doped polymer films for reversible optical storage [7125-03]

S. Fu, G. Wang, X. Wang, Q. Duanmu, Changchun Univ. of Science and Technology (China); W. Hu, M. Xie, Sichuan Univ. (China); Y. Liu, Northeast Normal Univ. (China)

$71250 X$ Spectroscopic, thermal, and recording properties of metal(II)-azo complexes for blu-ray recording materials [7125-81]

$X$. Li, Shanghai Institute of Optics and Fine Mechanics (China); Y. WU, Shanghai Institute of Optics and Fine Mechanics (China) and Heilongjiang Univ. (China); D. GU, F. Gan, Shanghai Institute of Optics and Fine Mechanics (China) 
7125 OY Polarization storage by two-photon absorption method in a diazobenzene/MMA copolymer [7125-33]

Y. Hu, Z. Zhang, S. Lei, J. Ding, M. Xu, W. Huang, Q. Zhang, Univ. of Science and Technology of China (China)

$71250 Z$ Photoinduced anisotropy in diarylethene/PMMA film [7125-43]

A. Chen, Jiangxi Science and Technology Normal Univ. (China) and East China Institute of Technology (China); S. Pu, Jiangxi Science and Technology Normal Univ. (China); Z. Le, East China Institute of Technology (China); W. Liu, Jiangxi Science and Technology Normal Univ. (China)

712510 Photochromic kinetics of diarylethenes bearing different alkyl chains in solution and in PMMA amorphous film [7125-40]

W. Liu, S. Pu, C. Fan, G. Liu, Jiangxi Science and Technology Normal Univ. (China)

712511 Photoregulated fluorescence switching of a photochromic diarylethene bearing fluorine atoms [7125-44]

H. Li, S. Pu, G. Liu, C. Fan, W. Miao, Jiangxi Science and Technology Normal Univ. (China)

712512 Full-color display of new photochromic diarylethene derivatives [7125-45]

P. Yan, S. Pu, W. Liu, G. Liu, Jiangxi Science and Technology Normal Univ. (China)

712513 Oxidative electrochemical switching of photochromic diarylethene compounds [7125-41]

C. Fan, S. Pu, W. Liu, T. Yang, G. Liu, Jiangxi Science and Technology Normal Univ. (China)

712514 Optical switching property of electromagnetically induced transparency in a $\wedge$ system [7125-147]

L. Zhang, J. Wang, X. Feng, L. Yang, X. Li, M. Zhao, Hebei Univ. (China)

712515 A liquid photochromic diarylethene for high speed photo switches [7125-122]

S. Dong, Tsinghua Univ. (China); J. Woo, Sangmyung Univ. (Korea, Republic of); Z. Chen,

Y. Tang, F. Zhang, Tsinghua Univ. (China)

\section{SESSION 4 NETWORK STORAGE AND MASS STORAGE SYSTEM}

712516 A virtual network computer's optical storage virtualization scheme [7125-82] J. Wang, Wuhan National Lab. for Optoelectronics, Huazhong Univ. of Science and Technology (China); H. Hu, China Electronics Technology Group Corp. (China); J. Wan, P. Wang, Wuhan National Lab. for Optoelectronics, Huazhong Univ. of Science and Technology (China)

712517 SMART reliability mechanism for very large storage systems [7125-100]

D. Luo, H. Zhong, C. Pei, W. Wu, C. Zhang, Huazhong Univ. of Science and Technology (China)

712518 Design and implementation of a data disaster recovery system based on storagevirtualization [7125-123]

J. Zhu, J. Zhou, Huazhong Univ. of Science and Technology (China); D. Zeng, PLA Commanding Communications (China); L. Qin, Huazhong Univ. of Science and Technology (China) 
712519 High-performance server-free backup model of content aware storage system [7125-134] Y. Wang, J. Zhou, L. Qin, X. Nie, K. Liu, Wuhan National Lab. for Optoelectronics, Huazhong Univ. of Science and Technology (China)

7125 1A Research on an IP disaster recovery storage system [7125-102]

D. Zeng, Y. Wang, PLA Commanding Communications Academy (China); J. Zhu, Huazhong Univ. of Science and Technology (China)

7125 1B An adaptive cryptographic accelerator for network storage security on dynamically reconfigurable platform [7125-119]

L. Tang, J.-N. Liu, D. Feng, W. Tong, Wuhan National Lab. for Optoelectronics, Huazhong Univ. of Science and Technology (China)

7125 1C Optimization of mass storage systems by quality of service [7125-15]

C. Wu, Q. Cao, S. Wan, L. Xiao, D. Huo, Huazhong Univ. of Science and Technology (China) and Wuhan National Lab. for Optoelectronics (China)

7125 1D A digital watermarking algorithm for color images using image correction [7125-04] J. Liu, Wuhan National Lab. for Optoelectronics, Huazhong Univ. of Science and Technology (China) and Wuhan Institute of Technology (China); H. Huang, Wuhan National Lab. for Optoelectronics, Huazhong Univ. of Science and Technology (China)

$71251 \mathrm{E}$ Design and performance evaluation of a read/write metadata service strategy for a largescale storage system [7125-143]

G. Zhou, Q. Cao, C. Wu, Huazhong Univ. of Science and Technology (China) and Wuhan National Lab. for Optoelectronics (China)

7125 IF A dynamic linear chain load balancing policy in MDS cluster [7125-144] Y. Su, Wuhan Univ. of Science and Engineering (China) and Wuhan National Lab. for Optoelectronics, Huazhong Univ. of Science and Technology (China); J. Zhou, Wuhan National Lab. for Optoelectronics, Huazhong Univ. of Science and Technology (China)

$71251 G \quad$ Content-aware network storage system supporting metadata retrieval [7125-149] K. Liu, L. Qin, J. Zhou, X. Nie, Huazhong Univ. of Science and Technology (China)

$71251 \mathrm{H} \quad$ Research on immune storage anomaly detection via user access behavior [7125-14] J. Huang, Y. Chen, Y. Fang, Wuhan National Lab. for Optoelectronics, Huazhong Univ. of Science and Technology (China)

$712511 \quad$ A new energy saving storage system: SERAID for disk array [7125-77] F. Wu, Wuhan National Lab. for Optoelectronics, Huazhong Univ. of Science and Technology (China); H. Hu, China Electronics Technology Group Corp. (China); K. Liu, Wuhan National Lab. for Optoelectronics, Huazhong Univ. of Science and Technology (China)

$71251 \mathrm{~J} \quad$ Approximate parameters analysis of a closed fork-join queve model in an object-based storage system [7125-72]

H. Y. Li, Y. Liu, Q. Cao, Huazhong Univ. of Science and Technology (China) 
$71251 \mathrm{~K} \quad$ Research on the evolutionary storage system [7125-23]

Y. Wang, Huazhong Univ. of Science and Technology (China); C. Xie, Wuhan National Lab. for Optoelectronics (China) F. Wang, Z. Lu, G. Jiang, Huazhong Univ. of Science and Technology (China)

$71251 \mathrm{~L} \quad$ Research on an immune authentication sub-system for networked storage [7125-13] J. Huang, H. Li, X. Li, Wuhan National Lab. for Optoelectronics, Huazhong Univ. of Science and Technology (China)

$71251 \mathrm{M}$ The research and design for a high availability object storage system [7125-60] L. Zhan, Z. Tan, Wuhan National Lab. for Optoelectronics, Huazhong Univ. of Science and Technology (China); P. Gu, Univ. of Central Florida (United States) and Microsoft Corp. (United States); J. Wan, Wuhan National Lab. for Optoelectronics, Huazhong Univ. of Science and Technology (China)

$71251 \mathrm{~N} \quad$ Research on ATCA-based content aware storage data gateway [7125-127]

Y. Wang, J. Zhou, L. Qin, H. Hong, Q. Guan, Wuhan National Lab. for Optoelectronics, Huazhong Univ. of Science and Technology (China)

712510 Design and implementation of an embedded backup system [7125-142] J. Liu, G. Liu, T. Yang, Wuhan National Lab. for Optoelectronics, Huazhong Univ. of Science and Technology (China)

7125 IP Research on bottlenecks of RAID controller hardware [7125-51]

Z. Tan, J. Chen, Wuhan National Lab. for Optoelectronics, Huazhong Univ. of Science and Technology (China); H. Hu, China Electronics Technology Group Corp. (China)

$71251 Q \quad$ Metadata distribution algorithm based on directory hash in mass storage system [7125-89] W. Wu, D. Luo, C. Pei, Wuhan National Lab. for Optoelectronics, Huazhong Univ. of Science and Technology (China)

$71251 R \quad$ A CDP method in an object-based file system [7125-78]

J. Yao, Q. Cao, H. Li, Wuhan National Lab. for Optoelectronics, Huazhong Univ. of Science and Technology (China)

7125 is Design and research on a multi-protocol RAID [7125-92]

C. Pei, D. Luo, C. Zhang, W. Wu, Wuhan National Lab. for Optoelectronics, Huazhong Univ. of Science and Technology (China)

\section{SESSION $5 \quad$ NON-VOLATILE MEMORY AND PHASE CHANGE MATERIALS}

$71251 \mathrm{~T} \quad$ Study of Si-doped $\mathrm{Sb}_{2} \mathrm{Te}_{3}$ film for low power and good data retention phase-change memory application [7125-59]

Y. Zhang, J. Feng, B. Cai, Shanghai Jiaotong Univ. (China)

$71251 \mathrm{U}$ Laser-induced structural, electrical, and optical properties evolution of phase change $\mathrm{Ge}_{2} \mathrm{Sb}_{2} \mathrm{Te}_{5}$ thin films [7125-159]

H. Sun, L. Hou, Y. Wu, Shanghai Institute of Optics and Fine Mechanics (China)

$71251 \mathrm{~V}$ Optical and structural properties of Sb and Sb-rich SiSb thin films [7125-131]

H. Huang, Y. Wang, F. Gan, Shanghai Institute of Optics and Fine Mechanics (China) 
7125 IW Phase transition kinetics of $\mathrm{Sb}_{2} \mathrm{Te}_{3}$ phase change thin films [7125-130]

F. Zhai, Y. Wang, Y. Wu, F. Gan, Shanghai Institute of Optics and Fine Mechanics (China)

$71251 \mathrm{X} \quad$ Array with phase change material $\mathrm{Si}_{2} \mathrm{Sb}_{2} \mathrm{Te}_{5}$ fabricated by UV-imprint lithography [7125-09] Y. Liu, Shanghai Nanotechnology Promotion Ctr. (China) and Shanghai Institute of Microsystem and Information Technology (China); X. Niu, Shanghai Nanotechnology Promotion Ctr. (China); Z. Song, Shanghai Institute of Microsystem and Information Technology (China); G. Min, Shanghai Nanotechnology Promotion Ctr. (China); W. Zhou, Shanghai Nanotechnology Promotion Ctr. (China) and Shanghai Institute of Microsystem and Information Technology (China); J. Zhang, Shanghai Nanotechnology Promotion Ctr. (China); T. Zhang, B. Liu, Shanghai Institute of Microsystem and Information Technology (China); Y. Wan, X. Li, Shanghai Nanotechnology Promotion Ctr. (China); J. Zhang, Shanghai Nanotechnology Promotion Ctr. (China) and Shanghai Institute of Microsystem and Information Technology (China); S. Feng, Shanghai Institute of Microsystem and Information Technology (China)

\section{SESSION 6 CODING, MANUFACTURING, AND TESTING TECHNIQUES}

$71251 Y \quad$ Ensuring long-term reliability of the data storage on optical disc [7125-54]

K. Chen, L. Pan, Tsinghua Univ. (China); B. Xu, W. Liu, Tsinghua Tongfan Optical Disc Ltd. Co. (China)

712512 Designing optical disk systems into audio/video products [7125-83]

J. Yang, Wuhan National Lab. for Optoelectronics, Huazhong Univ. of Science and Technology (China)

712520 Design and implementation of a channel decoder with LDPC code [7125-99]

D. Hu, P. Wang, J. Wang, Wuhan National Lab. for Optoelectronics, Huazhong Univ. of Science and Technology (China); T. Li, Dezhou Vocational and Technical College (China)

712521 Servo lens design for NVD optical pick-up [7125-37]

D. Wang, X. Cheng, J. Ma, Tsinghua Univ. (China)

712522 Multifunctional automatic tester for optical storage and lithography [7125-74] Y. Fan, W. Xu, C. Lu, Shanghai Institute of Optics and Fine Mechanics (China); Q. Liu, C. Guo, The National Ctr. for Nanoscience and Technology of China (China)

712523 Compatible optical pickup actuator for next generation versatile disc system [7125-58] L. Zhong, J. Ma, X. Cheng, B. Zhang, Tsinghua Univ. (China)

712524 Design of a physical format coding system [7125-94]

B. Hu, J. Pei, Q. Zhang, H. Liu, Y. Tang, Tsinghua Univ. (China)

712525 Designing a new multilevel run-length limited modulation code [7125-88]

X. Liu, J. Pei, L. Pan, H. Liu, Tsinghua Univ. (China)

712526 Research and implementation on improving I/O performance of streaming media storage system [7125-103]

Z. LU, Y. Wang, G. Jiang, Wuhan National Lab. for Optoelectronics, Huazhong Univ. of

Science and Technology (China) 
712527 An adaptive data placement scheme for scaleable object storage system [7125-112] Y. Luo, W. Deng, Hubei Univ. (China)

712528 Review on the optical disc formats [7125-161]

$\mathrm{H}$. He, Shanghai Institute of Optics and Fine Mechanics (China)

712529 Research on high density data storage technology [7125-120]

L. Xiao, D. Hu, Wuhan National Lab. for Optoelectronics, Huazhong Univ. of Science and Technology (China)

7125 2A A new system of observing and measuring magnetic domain [7125-57]

Y. Yang, Shanghai Institute of Optics and Fine Mechanics (China) and Graduate Univ. of Chinese Academy of Sciences (China); W. Xu, Shanghai Institute of Optics and Fine Mechanics (China)

7125 2B Analytic solution for damping coefficients of six-wire-suspension actuator in optical pickup [7125-06]

B. Zhang, J. Ma, L. Pan, X. Cheng, L. Zhong, Tsinghua Univ. (China)

$71252 \mathrm{C}$ Triplet collimator lens design of blu-ray disc optical pick-up [7125-50]

L. Li, J. Lu, L. Pan, J. Ma, Tsinghua Univ. (China)

7125 2D Design and applications of semiconductor components in OPU [7125-84]

J. Yang, Wuhan National Lab. for Optoelectronics, Huazhong Univ. of Science and Technology (China)

$71252 \mathrm{E} \quad$ Dynamic testing system for hybrid magneto-optical recording [7125-73]

L. Chen, W. Xu, Y. Fan, Q. Zhu, Shanghai Institute of Optics and Fine Mechanics (China)

$71252 \mathrm{~F}$ The power spectrum computation and spectrum performance evaluation of a new optical modulation code [7125-16]

Z. Ye, D. Hu, Wuhan National Lab. for Optoelectronics, Huazhong Univ. of Science and Technology (China)

$71252 \mathrm{G}$ Research on a manufacturing on demand (MOD) system based on DVD download specification [7125-67]

F. Wang, D. LU, H. Hu, L. Pan, B. Hu, X. Liu, Tsinghua Univ. (China)

Author Index 


\title{
Conference Committees
}

\author{
Conference Chair
}

Fuxi Gan, Shanghai Institute of Optics and Fine Mechanics (China)

Cochair

Chaohui Ye, Wuhan National Laboratory for Optoelectronics (China)

International Advisory Committee

Di Chen, CHEN and Associates (United States)

Fuxi Gan, Shanghai Institute of Optics and Fine Mechanic (China)

Lisong Hou, Shanghai Institute of Optics and Fine Mechanics (China)

Akiyoshi Itoh, Nihon University (Japan)

Bo Liu, Data Storage Institute (Singapore)

Masud Mansuripur, University of Arizona (United States)

Liangmo Mei, Shandong University (China)

Yoshinobu Mitsuhashi, Japan Science and Technology Agency

(Japan)

Koichi Ogawa, University of Tokyo (Japan)

Takeo Ohta, Ovonic Phase-Change Laboratory (Japan)

Young-Pil Park, Yonsei University (Korea, Republic of)

Junji Tominaga, National Institute of Advanced Industrial Science and Technology (Japan)

Din Ping Tsai, National Taiwan University (Taiwan, China)

Matthias Wuttig, RWTH Aachen (Germany)

Duanyi Xu, Tsinghua University (China)

Chaohui Ye, Wuhan National Laboratory for Optoelectronics (China)

Jimmy Zhu, Carnegie Mellon University (United States)

\section{Organizing Committee}

Jianqiang Zhu, Chair, Shanghai Institute of Optics and Fine Mechanic (China)

Jiaxin Zhao, Cochair, Wuhan Hi-Tech Holding Group Company, Ltd. (China)

Xiangshui Miao, Cochair, Huazhong University of Science and Technology (China)

Donghong Gu, Shanghai Institute of Optics and Fine Mechanics (China)

Jie He, National Natural Science Foundation (China)

Diqing Hu, Wuhan National Laboratory for Optoelectronics (China) 
Jianwei Li, Wuhan Optics Valley NOE-Tech Development Company Ltd. (China)

Baining Ouyang, Wuhan Hi-Tech Holding Group Company, Ltd. (China)

Longfa Pan, Optical Memory National Engineering Research Center (China)

Huiping Pu, Linfair Engineering (H.K.) Company, Ltd. (Hong Kong, China)

Hao Ruan, National Engineering Research Center for Optical Discs and Applications (China)

Xianghua Xu, TCL Entertainment Company Ltd. (China)

Xiaohu You, Xinguanglian Optical Discs Company, Ltd. (China)

Yuanfan Zhou, Zhanjiang Huali Jin Video Plate Company, Ltd. (China)

\section{Program Committee}

Changsheng Xie, Chair, Wuhan National Laboratory for Optoelectronics (China)

Lisong Hou, Cochair, Shanghai Institute of Optics and Fine Mechanics (China)

Qingyuan Jin, Cochair, Fudan University (China)

Ken Chen, Optical Memory National Engineering Research Center (China)

Dan Feng, Wuhan National Laboratory for Optoelectronics (China)

Xiufeng Han, Institute of Physics (China)

Mingju Huang, He'nan University (China)

Wenhao Huang, University of Science and Technology of China (China)

Weiquan Li, National Engineering Research Center for Optical

Discs and Applications (China)

Yinyin Lin, Fudan University (China)

Qian Liu, National Center of Nano Science and Technology (China)

Xiangshui Miao, Huazhong University of Science and Technology (China)

Zhitang Song, Shanghai Institute of Microsystem and Information Technology (China)

Xiudong Sun, Harbin Institute of Technology (China)

Wendong $X_{\mathbf{u}}$, Shanghai Institute of Optics and Fine Mechanics (China)

Xiaofei Yang, Huazhong University of Science and Technology (China) 
Editor

Fuxi Gan, Shanghai Institute of Optics and Fine Mechanics (China)

Co-editors

Changsheng Xie, Wuhan National Laboratory for Optoelectronics (China)

Lisong Hou, Shanghai Institute of Optics and Fine Mechanics (China)

Secretariat

Yiqun Wu, Secretary General, Shanghai Institute of Optics and Fine Mechanics (China)

Yang Wang, Shanghai Institute of Optics and Fine Mechanics (China)

Hongxiang Lin, Shanghai Institute of Optics and Fine Mechanics (China)

Chang Fang, Wuhan National Laboratory for Optoelectronics (China) Yan Liu, Wuhan Hi-Tech Holding Group Company, Ltd. (China) 
Downloaded From: https://www.spiedigitallibrary.org/conference-proceedings-of-spie on 26 Apr 2023

Terms of Use: https://www.spiedigitallibrary.org/terms-of-use 